\title{
Precautionary Savings in a Small Open Economy Revisited
}

\author{
Agustín Roitman
}




\title{
IMF Working Paper
}

\author{
Middle East and Central Asia Department
}

\section{Precautionary Savings in a Small Open Economy Revisited}

\author{
Prepared by Agustín Roitman ${ }^{1}$
}

Authorized for distribution by Paul Cashin

November 2011

\section{This Working Paper should not be reported as representing the views of the IMF.} The views expressed in this Working Paper are those of the author(s) and do not necessarily represent those of the IMF or IMF policy. Working Papers describe research in progress by the author $(s)$ and are published to elicit comments and to further debate.

\begin{abstract}
A common assumption in standard economic models is that agents are risk-averse and prudent, and it is often argued that prudence is necessary to generate precautionary savings. This paper shows that prudence is not necessary to generate precautionary savings in small open economy models with more than two periods. A new class of preferences, which enables the isolation of the effect of risk aversion on precautionary savings, is introduced. The effects of changes in risk aversion, interest rates, and persistence and volatility of shocks on average asset holdings are qualitatively identical to the ones observed for standard constant-elasticity-of-substitution preferences. These results show that the almost universal assertion in the literature - that only prudent consumers can generate positive levels of precautionary savings - is simply incorrect.
\end{abstract}

JEL Classification Numbers: E21, F30, F41

Keywords: Saving; precautionary savings; risk aversion; prudence; preferences

Author’s E-Mail Address: aroitman@imf.org

\footnotetext{
${ }^{1}$ The author would like to thank Emine Boz, Pablo D’Erasmo, Matias Herrera Dappe, Sebastian Miller, Rong Qian, Carmen Reinhart, Cesar Sosa-Padilla as well as participants at the University of Maryland at College Park international and macro seminars, for helpful comments and suggestions. The author also benefited from long and insightful conversations with Enrique Mendoza, and is extremely grateful to Carlos Vegh for invaluable guidance. All remaining errors are exclusively the author's responsibility.
} 


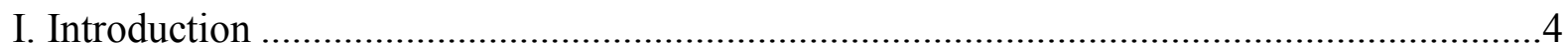

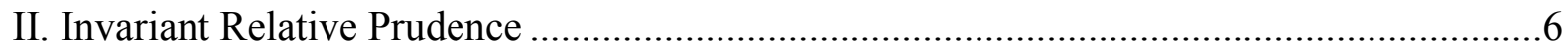

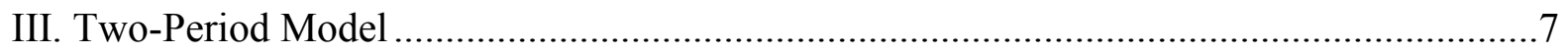

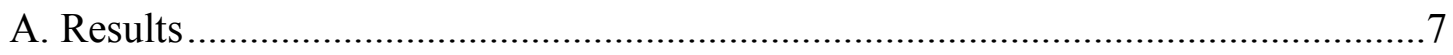

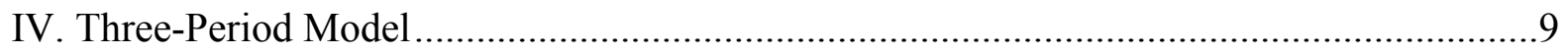

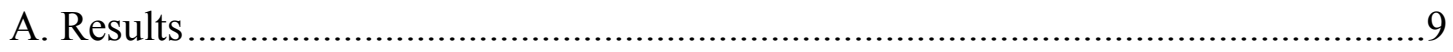

V. Volatility, Intertemporal Distortions, Risk Aversion, and Interest Rates ...........................10

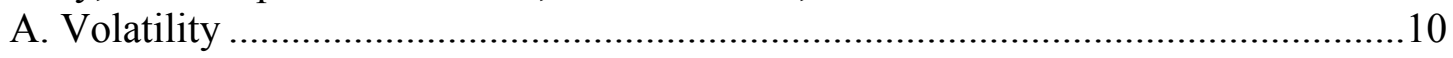

B. Intertemporal Distortions ...............................................................................

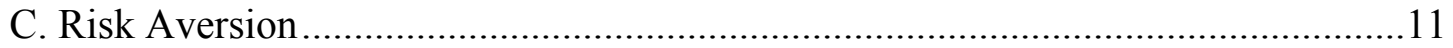

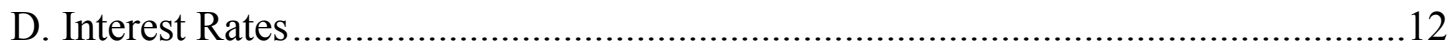

VI. Imprudence and Higher Savings..................................................................................12

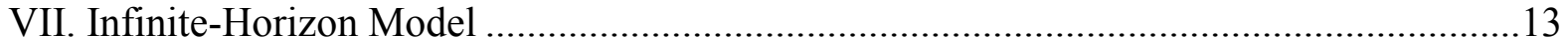

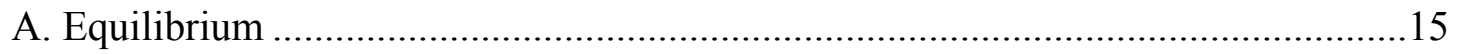

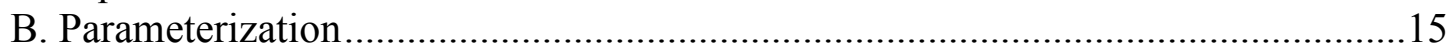

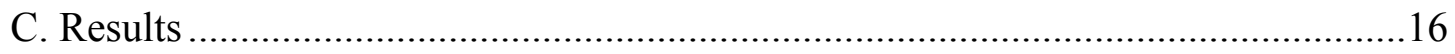

VIII. Finite-Horizon Model ……………......................................................................

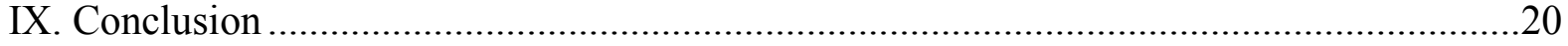

Relative Prudence and Relative Risk Aversion ........................................................22

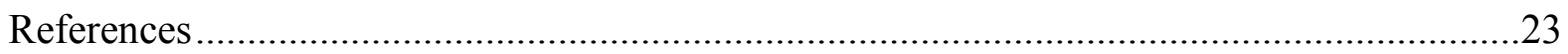

Appendix

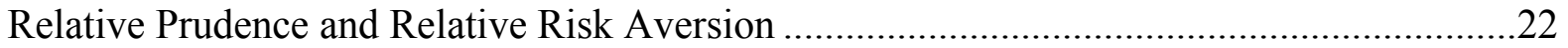

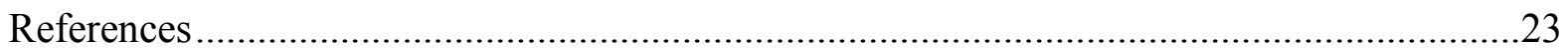

Tables

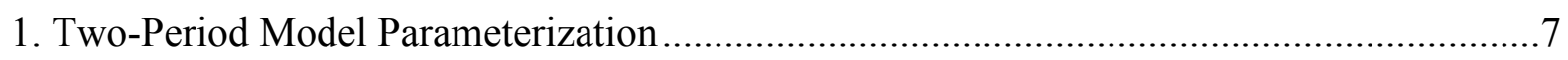

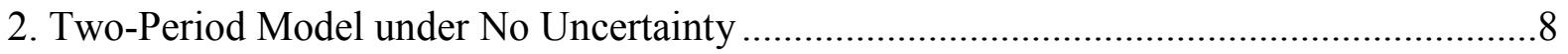

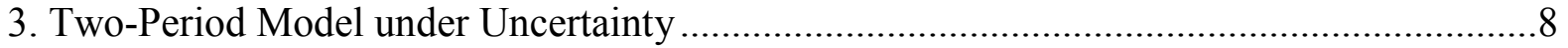

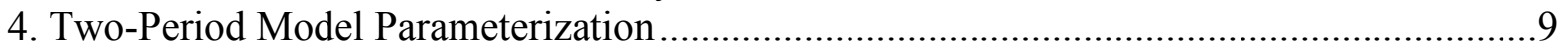

5. Three-Period Model under No Uncertainty ………..........................................................9

6. Three-Period Model under Uncertainty …………..........................................................

7. Endowments in Periods Two and Three .......................................................................

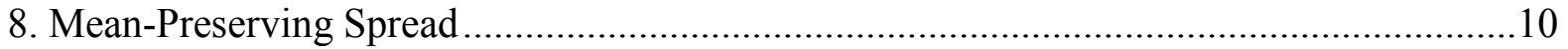

9. Intertemporal Distortions under No Uncertainty ………..................................................11 


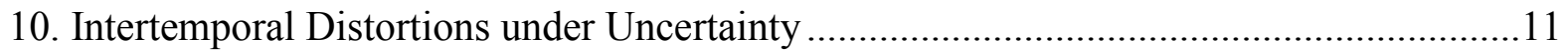

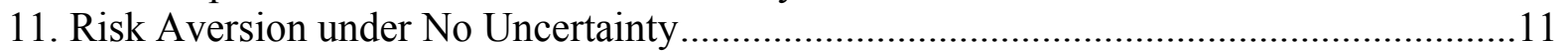

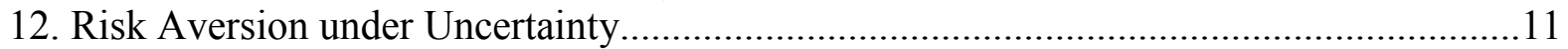

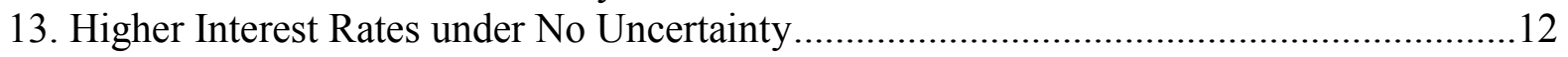

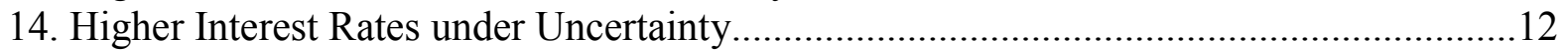

15. Intertemporal Distortions and Risk Aversion under No Uncertainty ................................13

16. Intertemporal Distortions and Risk Aversion under Uncertainty ......................................13

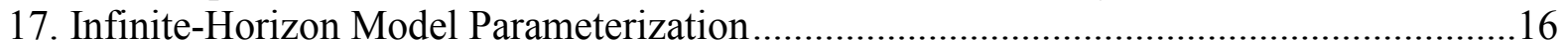

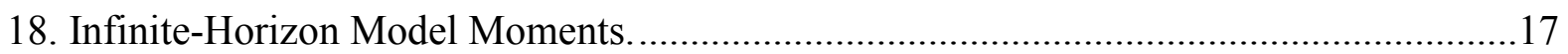

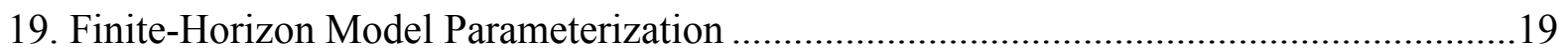

20. Forty-Period Model with Low Volatility ..................................................................19

21. Forty-Period Model with High Volatility ......................................................................19

22. Two-Hundred-Period Model with High Volatility ...........................................................19

23. Two-Hundred-Period Model with High Volatility ............................................................19 


\section{INTRODUCTION}

Despite the large number of studies on the determinants of precautionary savings, confusion still prevails. Theoretical results in two-period models (e.g., Leland, 1968) point out that the degree of prudence (i.e., the sign of the third derivative) is the key to determining whether precautionary savings are positive or negative. In particular, prudence (i.e., a positive third derivative) is necessary and sufficient to generate positive precautionary savings when agents live for only two periods. On the other hand, as shown by Huggett and Ospina (2001) the degree of prudence is completely irrelevant in an infinite-horizon model with heterogeneous agents and independent and identically distributed shocks. ${ }^{2}$

It is important to distinguish between the concept of risk aversion" and prudence." Risk aversion refers to the fact that agents dislike risk (i.e., uncertainty) and like to smooth consumption across time; prudence refers to the fact that agents like to be prepared for a very bad outcome (i.e., having a buffer stock of assets would enable them to dissave instead of reducing consumption) or a very long stream of negative shocks. The degree of risk aversion is determined by the concavity of the utility function used to represent preferences, whereas the degree of prudence is determined by the convexity of the marginal utility (i.e., the third derivative of the utility function).

This paper shows that in small open economy models with more than two periods, prudence is not necessary to generate precautionary savings. This result holds both in finite and infinite-horizon models. This is the first study presenting an example of a class of preferences corresponding to risk-averse but imprudent agents. ${ }^{3}$ Having an explicit functional form for this kind of preferences proves useful to studying (both qualitatively and quantitatively) the effects of volatility, risk aversion, interest rates, intertemporal distortions, and persistence of shocks on precautionary savings levels in a small open economy.

Inspired by Huggett and Ospina (2001), and using the new class of preferences presented in this paper, one can show, first, that regardless of the structure of shocks, in an infinitehorizon, small open economy model with a representative agent, prudence (i.e., positive third derivative) is completely irrelevant in generating positive precautionary savings. ${ }^{4}$ Second,

\footnotetext{
${ }^{2}$ The empirical literature is divided on the existence of precautionary motives at the household level. For a survey on this, see Browning and Lusardi (1996).

${ }^{3}$ From now on, prudence or imprudence will be referring to the definition used in Kimball (1990). This new class of preferences is characterized by a constant and invariant coefficient of relative prudence which is completely independent from the coefficient of relative risk aversion (which is not the case in standard constant elasticity of substitution (CES) preferences).

${ }^{4}$ As pointed out by Aiyagari (1994) the key determinants of precautionary savings are: the infinite horizon and a borrowing constraint, and not the degree of (im)prudence (i.e., the sign of the third derivative).
} 
this result holds in finite horizon models, for a given structure of shocks, provided that the time horizon is sufficiently long.

The particular class of preferences presented in this paper is characterized by two salient features. First, a negative third derivative, and, second, a constant and invariant coefficient of relative prudence; both of which are crucial to the study of precautionary saving behavior in small open economies. ${ }^{5}$ The objective of the paper is to answer the following two questions. First, is it possible to have positive precautionary savings in the presence of imprudent agents (i.e., preferences characterized by a negative third derivative)? Second, what are the key elements driving this result? As is standard in economic theory, the class of preferences considered in this study displays risk aversion but, at the same time, it also displays a nonstandard feature: imprudence (as defined by Kimball, 1990). On the one hand, risk aversion provides incentives to increase savings, but on the other hand imprudence provides incentives to save less in the face of uncertainty. The novelty of this class of preferences is the possibility of isolating how changes in risk aversion (without changing the degree of prudence) affect precautionary savings. ${ }^{6}$

Interestingly enough, constant elasticity of substitution (CES) preferences are characterized by a constant coefficient of relative prudence, but it is the same parameter affecting risk aversion that also determines relative prudence. Therefore, it is difficult to disentangle whether precautionary savings are, say, higher, because of higher risk aversion, higher relative prudence, or both. The class of preferences considered in this study displays a constant coefficient of relative prudence, which is completely independent of the parameters defining the degree of risk aversion. This shows that risk aversion does not necessarily imply prudence. In fact, in this case agents are risk-averse and imprudent. Furthermore, depending on the structure of the environment (i.e., shocks, interest rates, intertemporal distortions), precautionary savings can be higher or lower under uncertainty, compared to the case of perfect foresight.

As highlighted by Aiyagari (1994), in a two-period model, borrowing constraints can be ignored by making suitable assumptions about the time profile of the endowment; but in an infinite-horizon model, borrowing constraints cannot be ignored. The combination of uncertainty, infinite horizon, and a borrowing constraint implies that precautionary savings will always be higher compared to the case of perfect foresight, regardless of whether agents are prudent or imprudent. Intuitively, when an economy faces borrowing constraints and uncertainty, and the time horizon is long enough, it fears getting a sufficiently large sequence of bad shocks (i.e., low endowment realizations) which would push it toward the constraint

\footnotetext{
${ }^{5}$ The coefficient of relative prudence (as defined by Kimball (1990)) is not only constant but also completely independent of particular parameters characterizing preferences (e.g., risk aversion).

${ }^{6}$ See the Appendix for the exact definition and computation of relative risk aversion and relative prudence.
} 
and force it to consume its income without the possibility of smoothing consumption. This behavior will hold, irrespective of whether agents are prudent or imprudent.

Section II presents the utility function corresponding to the particular class of preferences introduced in this paper. Section III shows that in a two-period model with risk-averse but imprudent agents, average asset holdings are lower in an environment with uncertainty than without. Section IV considers a three-period model identical to the one in Section III except that it has one more period. In Section V, I conduct a set of experiments in order to determine how average asset holdings are affected by changes in volatility, risk aversion, interest rates, and intertemporal distortions. In Section VI, I construct a particular example where, in spite of agents being imprudent, savings levels are higher under uncertainty. Section VII presents an infinite-horizon version of the basic small open economy model under uncertainty calibrated for Mexico, and uses this model to assess the effects of persistence and volatility of shocks, and of interest rates and risk aversion on precautionary savings levels. Section VIII addresses the question of whether it is necessary to have an infinite horizon in order to generate positive precautionary savings. Section IX concludes.

\section{Invariant Relative Prudence}

We consider the particular class of preferences characterized by the following utility function:

$$
u\left(c_{t}\right)=a c_{t}-b c_{t}^{3}
$$

where $a$ and $b$ are parameters and $c_{t}$ is consumption in period $t .^{7}$ Notice that this function is increasing, strictly concave, and has a negative third derivative (i.e., $u^{\prime \prime \prime}<0$ ). One salient feature of these preferences is that they have a constant and invariant coefficient of relative prudence which is completely unrelated to the degree of risk aversion. As a matter of fact, it is constant and independent of the particular parameters defining the concavity of the utility function. ${ }^{8}$ (See the Appendix for details.)

Intuitively, this particular class of preferences is characterized by risk aversion and imprudence and constitutes, to the best of my knowledge, the first explicit example that risk aversion does not necessarily imply prudence.

\footnotetext{
${ }^{7}$ Notice that for sufficiently high values of the parameter $a$, relative to the parameter $b$, the marginal utility of consumption is positive.

${ }^{8}$ Note that for the CES class of preferences, the coefficient of relative prudence is constant but it depends on the same parameter defining the degree of risk aversion.
} 


\section{Two-Period MODEL}

I consider a two-period small open economy model where the endowment of period two is stochastic. Using this model I will show that the sign of the third derivative determines whether precautionary savings are positive or negative. There is only one tradable good and the economy is perfectly integrated into world capital markets (i.e., agents can borrow from and lend to the rest of the world at a given real interest rate). The real interest rate is taken as given $(r \geq 0)$. The budget constraint for period two is

$$
\begin{aligned}
& 0=(1+r) b_{1}+y_{2}^{L}-c_{2}^{L} \\
& 0=(1+r) b_{1}+y_{2}^{H}-c_{2}^{H}
\end{aligned}
$$

where $y_{2}{ }^{H}$ and $y_{2}{ }^{L}$ are the endowments received in period two in the good and bad states of nature respectively. There is only one non-contingent bond $\left(b_{1}\right)$ and consumption in the good and bad states of nature are given by $c_{2}{ }^{H}$ and $c_{2}{ }^{L}$ respectively.

The budget constraint for period one is:

$$
b_{1}=(1+r) b_{0}+y_{1}-c_{1}
$$

where initial assets $\left(b_{0}\right)$ are given.

Preferences are given by:

$$
U=u\left(c_{1}\right)+\beta u\left(c_{2}\right)
$$

where $(\beta \in[0,1])$ is the subjective discount factor and the period utility is given by the utility function presented in Section II.

The economy maximizes (5), choosing $c_{1}, c_{2}{ }^{H}$ and $c_{2}{ }^{L}$ subject to (2), (3), and (4).

\section{A. Results}

We compare the level of average asset holdings under perfect foresight to the corresponding one under uncertainty, for a given set of parameters (Table 1). In order to solve the model, we assume the following parameterization. ${ }^{9}$

\begin{tabular}{cccccccc}
\multicolumn{7}{c}{ Table 1. Two-Period Model Parameterization } \\
\hline$a$ & $b$ & $r$ & $\beta$ & $y_{1}$ & $y_{2}{ }^{L}$ & $y_{2}{ }^{H}$ & $b_{0}$ \\
\hline 6 & $1 / 3$ & 0.01 & 0.98 & 1.5 & 1 & 2 & 0 \\
\hline
\end{tabular}

\footnotetext{
${ }^{9}$ Here, and for all subsequent experiments, we use the same probabilities $(0.5)$ for the low and high states of nature.
} 
Following Durdu et al. (2007), precautionary savings are defined as the difference between average assets holdings under uncertainty and its counterpart under no uncertainty. As we can see, under no uncertainty, the economy has a perfectly smooth consumption path and average assets holdings are zero.

Table 2. Two-Period Model under No Uncertainty

\begin{tabular}{ccccc}
\hline Period & Endowment & Assets & Consumption & $E$ (assets) \\
\hline & & & & \\
1 & 1.5 & 0 & 1.5064 & 0 \\
2 & 1.5 & -0.0064 & 1.4936 & -0.0064 \\
\hline
\end{tabular}

As pointed out in Leland (1968), introducing uncertainty will generate positive precautionary savings only if the third derivative is positive. As can be seen in Table 3, given that the class of preferences considered in this study displays a negative third derivative, average assets holdings are negative and therefore precautionary savings are negative. Intuitively, since agents are imprudent, this economy chooses to hold more debt (save less) under uncertainty compared to the case of no uncertainty.

Table 3. Two-Period Model under Uncertainty

\begin{tabular}{ccccc}
\hline Period & Endowment & Assets & Consumption & $E$ (assets) \\
\hline & & & & \\
1 & 1.5 & 0 & 1.5476 & 0 \\
2 & 1.0 & -0.0476 & 0.9519 & -0.0476 \\
& 2.0 & & 1.9519 & \\
\hline
\end{tabular}

This result can be better understood considering two elements; the Euler equation and the sign of the third derivative.

$$
u^{\prime}\left(c_{1}\right)=p u^{\prime}\left(c_{2}^{H}\right)+(1-p) u^{\prime}\left(c_{2}^{L}\right)=E\left[u^{\prime}\left(c_{2}\right)\right]
$$

Notice that depending on whether $u^{\prime}(c)$ is linear, strictly convex, or strictly concave,

$$
\begin{aligned}
& E\left[u^{\prime}\left(c_{2}\right)\right]=u^{\prime}\left[E\left(c_{2}\right)\right] \\
& E\left[u^{\prime}\left(c_{2}\right)\right]>u^{\prime}\left[E\left(c_{2}\right)\right] \\
& E\left[u^{\prime}\left(c_{2}\right)\right]<u^{\prime}\left[E\left(c_{2}\right)\right]
\end{aligned}
$$

and this in turn depends on whether $u^{\prime \prime \prime}(c)=0, u^{\prime \prime \prime}(c)>0$ or $u^{\prime \prime \prime}(c)<0$ respectively. Using these two pieces of information, it is easy to see that:

$$
\begin{gathered}
u^{\prime}\left(c_{1}\right)=E\left[u^{\prime}\left(c_{2}\right)\right] \\
u^{\prime}\left(c_{1}\right)>E\left[u^{\prime}\left(c_{2}\right)\right]
\end{gathered}
$$




$$
u^{\prime}\left(c_{1}\right)<E\left[u^{\prime}\left(c_{2}\right)\right]
$$

Therefore, the Euler equation and the sign of the third derivative determine whether precautionary savings are positive or negative.

\section{Three-Period MOdeL}

In this section, and in order to show that the result of the previous section holds when the time horizon is finite, I consider the exact same model of a small open economy, but with one more time period.

\section{A. Results}

The parameterization used to solve the model is the following:

\begin{tabular}{cccccccccc}
\multicolumn{1}{c}{ Table 4. Three-Period Model Parameterization } \\
\hline$a$ & $b$ & $r$ & $\beta$ & $y_{1}$ & $y_{2}{ }^{L}$ & $y_{2}{ }^{H}$ & $y_{3}{ }^{L}$ & $y_{3}{ }^{H}$ & $b_{0}$ \\
\hline 6 & $1 / 3$ & 0.01 & 0.98 & 1.5 & 1 & 2 & 1 & 2 & 0 \\
\hline
\end{tabular}

As we can see from Table 5 below, the economy still achieves full consumption smoothing under no uncertainty.

Table 5. Three-Period Model under No Uncertainty

\begin{tabular}{|c|c|c|c|c|}
\hline Period & Endowment & Assets & Consumption & $E$ (assets) \\
\hline 1 & 1.5 & 0 & 1.5 & 0 \\
\hline 2 & 1.5 & -0.0085 & 1.4957 & -0.0085 \\
\hline 3 & 1.5 & -0.0043 & 1.4957 & -0.0043 \\
\hline \multicolumn{5}{|c|}{ Table 6. Three-Period Model under Uncertainty } \\
\hline Period & Endowment & Assets & Consumption & $E$ (assets) \\
\hline 1 & 1.5 & 0 & 1.5767 & 0 \\
\hline \multirow[t]{2}{*}{2} & 1.0 & -0.00767 & 1.2613 & -0.0767 \\
\hline & 2.0 & -0.00767 & 1.7487 & \\
\hline \multirow[t]{2}{*}{3} & 1.0 & -0.3387 & 0.6579 & -0.0824 \\
\hline & 2.0 & 0.01739 & 2.1757 & \\
\hline
\end{tabular}

It then follows that introducing uncertainty makes the economy save less (i.e., hold more debt) than in the case of no uncertainty (Table 6). Average asset holdings (fifth column) are negative in periods two and three. And again, this result is caused by the sign of the third derivative. 


\section{VOlATIlity, INTERTEMPORAL DistorTiOns, RISK AVERSION, AND INTEREST RATES}

In order to better understand how strong the imprudence effect" is, this section presents four experiments. I will study the effects of the volatility of the endowment, the mean of the endowment (i.e., intertemporal distortion), risk aversion, and interest rates on precautionary savings levels.

\section{A. Volatility}

Does higher volatility increase or decrease precautionary savings? In order to answer this question, I will use the benchmark parameterization (Table 4). To assess the effect of volatility I will change the variance of the endowment distribution in periods two and three (Table 7), preserving the mean (i.e., mean-preserving spread).

Table 7. Endowments in Periods Two and Three

\begin{tabular}{llll}
\hline$y_{2}{ }^{L}$ & $y_{2}{ }^{H}$ & $y_{3}{ }^{L}$ & $y_{3}{ }^{H}$ \\
\hline 0.7 & 2.3 & 0.7 & 2.3 \\
\hline
\end{tabular}

Table 8. Mean-Preserving Spread

\begin{tabular}{ccccc}
\hline Period & Endowment & Assets & Consumption & $E$ (assets) \\
\hline & & & & \\
1 & 1.5 & 0 & 1.6841 & 0 \\
2 & 0.7 & -0.1841 & 1.1632 & -0.1841 \\
& 2.3 & -0.1841 & 1.8966 & \\
3 & 0.7 & -0.6491 & 0.0444 & -0.2158 \\
& 2.3 & 0.2175 & 2.5196 & \\
\hline
\end{tabular}

Notice that in this case, higher volatility implies lower savings (i.e., the debt is higher). In Table 6 , total average asset holdings are -0.1591 whereas now, with a higher variance in the endowment, total average asset holdings are -0.3999 (Table 8).

This result could capture the empirical observation that developing countries, having more volatile output than industrialized countries, hold, on average, more debt. This is a result of the concavity of the first derivative of the utility function.

\section{B. Intertemporal Distortions}

In this case the idea is to evaluate whether a lower endowment in period three provides incentives to save more in good times in order to smooth consumption across time. Notice that in this case $y_{3}{ }^{H}=y_{3}{ }^{L}=0$. 
Table 9. Intertemporal Distortions under No Uncertainty

\begin{tabular}{ccccc}
\hline Period & Endowment & Assets & Consumption & $E$ (assets) \\
\hline & & & & \\
1 & 1.5 & 0 & 1.0218 & 0 \\
2 & 1.5 & 0.4782 & 0.9964 & 0.4782 \\
3 & 0 & 0.9866 & 0.9964 & 0.9866 \\
\hline
\end{tabular}

Table 10. Intertemporal Distortions under Uncertainty

\begin{tabular}{ccccc}
\hline Period & Endowment & Assets & Consumption & $E$ (assets) \\
\hline \multirow{4}{*}{1} & & & & \\
2 & 1.5 & 0 & 1.0422 & 0 \\
& 1.0 & 0.4578 & 0.7348 & 0.4578 \\
3 & 2.0 & 0.4578 & 1.2373 & \\
& 0.0 & 0.7276 & 0.7348 & 0.9763 \\
& 0.0 & 1.2251 & 1.2373 & \\
\hline
\end{tabular}

As we can see in Tables 9 and 10, the imprudence effect" is stronger than the intertemporal distortion effect, and this is why total average asset holdings are still lower under uncertainty (1.4341) than in the no-uncertainty case (1.4648). But at the same time, it is easy to see that an intertemporal distortion involving a lower endowment in period 3 implies higher savings. To see this, one should compare Table 9 and Table 5 for the no-uncertainty case and Tables 10 and 6 for the cases with uncertainty. In both cases, a lower endowment in period 3 generates higher incentives to save in periods 1 and 2; this is caused by the concavity (i.e., risk aversion) of preferences. Consumers might be imprudent, but they are still risk-averse and, as a consequence, they want to smooth consumption.

\section{Risk Aversion}

In this case $a=5$, which implies a higher relative risk aversion. Our interest here is to compare these results with the benchmark.

Table 11. Risk Aversion under No Uncertainty

\begin{tabular}{ccccc}
\hline Period & Endowment & Assets & Consumption & $E$ (assets) \\
\hline \multicolumn{5}{c}{} \\
1 & 1.5 & 0 & 1.5062 & 0 \\
2 & 1.5 & -0.0062 & 1.4968 & -0.0062 \\
3 & 1.5 & -0.0031 & 1.4968 & -0.0031 \\
\hline \multicolumn{5}{c}{ Table 12. Risk Aversion under Uncertainty } \\
\hline Period & Endowment & Assets & Consumption & $E$ (assets) \\
\hline \multicolumn{5}{c}{1} \\
2 & 1.5 & 0 & 1.5745 & 0 \\
3 & 1.0 & -0.0745 & 1.2623 & -0.0745 \\
3 & 2.0 & -0.0745 & 1.7498 & -0.0812 \\
& 1.0 & -0.3375 & 0.6591 & \\
\hline
\end{tabular}


Total average asset holdings under no uncertainty (Table 11) are -0.0093, and under uncertainty (Table 12) -0.1557. Comparing these results to the benchmark, we can see that under no uncertainty, total average asset holdings are -0.0128 (Table 5) and under uncertainty (Table 6) are -0.1591. Thus, we conclude, from Tables 11 and 12, that higher relative risk aversion implies higher savings.

\section{Interest Rates}

One would expect that higher interest rates generate an increase in average asset holdings. In this case, $r=0.02$.

Table 13. Higher Interest Rates under No Uncertainty

\begin{tabular}{ccccc}
\hline Period & Endowment & Assets & Consumption & $E$ (assets) \\
\hline & & & & \\
1 & 1.5 & 0 & 1.5003 & 0 \\
2 & 1.5 & -0.0003 & 1.4998 & -0.0003 \\
3 & 1.5 & -0.0002 & 1.4998 & -0.0002 \\
\hline
\end{tabular}

Table 14. Higher Interest Rates under Uncertainty

\begin{tabular}{ccccc}
\hline Period & Endowment & Assets & Consumption & $E$ (assets) \\
\hline \multirow{4}{*}{1} & 1.5 & 0 & 1.5688 & 0 \\
2 & 1.0 & -0.0688 & 1.2632 & -0.0688 \\
& 2.0 & -0.0688 & 1.7531 & \\
3 & 1.0 & -0.3333 & 0.6600 & -0.0783 \\
& 2.0 & 0.1767 & 2.1803 & \\
\hline
\end{tabular}

We can see that savings are lower under uncertainty, compared to the no-uncertainty case. But comparing Table 14 and Table 6, it is easy to see that higher interest rates do generate higher average asset holdings. In this case (Table 14) total average asset holdings under uncertainty are -0.1471 , which is higher than -0.1591 (Table 6).

So the main message of this section is to highlight that except for an increase in volatility, increases in risk aversion, interest rates, and intertemporal distortions all have the exact same qualitative effects as in the case of the CES preferences. Obviously, a mean-preserving spread increase in volatility generates lower savings instead of higher (which is what one would expect under CES preferences) because of the concavity of the first derivative of the utility function.

\section{IMPRUDENCE AND HIGHER SAVINGS}

A legitimate question is whether it is possible to generate higher savings under uncertainty for this particular class of preferences (i.e., positive precautionary savings despite $\mathrm{u}^{\prime \prime \prime}<0$ ). 
As we saw in the previous section, intertemporal distortions or increases in risk aversion are not enough to undo the effect of imprudence (i.e., lower savings under uncertainty). For this reason, we construct an example in which there is an intertemporal distortion in period $3\left(y_{3}{ }^{H}\right.$ $=y_{3}{ }^{L}=0$ ) but also a change in relative risk aversion across time, so in this case the parameter $a$ in the utility function assumes a different value for period $3\left(a_{1}=49, a_{2}=49, a_{3}=3\right)$.

\begin{tabular}{|c|c|c|c|c|}
\hline Period & Endowment & Assets & Consumption & $E$ (assets) \\
\hline 1 & 2.5 & 0 & 4.8123 & 0 \\
\hline 2 & 2.5 & -2.3123 & 0.0827 & -2.3123 \\
\hline 3 & 0 & 0.0819 & 0.0827 & 0.0819 \\
\hline
\end{tabular}

Table 16. Intertemporal Distortions and Risk Aversion under Uncertainty

\begin{tabular}{ccccc}
\hline Period & Endowment & Assets & Consumption & $E$ (assets) \\
\hline \multirow{4}{*}{1} & 2.5 & 0 & 4.4757 & 0 \\
2 & 2.0 & -1.9756 & 0.0017 & -1.9756 \\
& 3.0 & -1.9756 & 0.5048 & \\
3 & 0.0 & 0.003 & 0.0030 & 0.2514 \\
& 0.0 & 0.4998 & 0.5048 & \\
\hline
\end{tabular}

From Tables 15 and 16, one can see that savings are higher under uncertainty. So, in order to undo the imprudence effect" it is necessary to combine a drastic increase in risk aversion and at the same time a negative shock" in endowment in the last period. These two forces together are stronger than imprudence; therefore the economy ends up saving more under uncertainty (Table 16) than in the case of no uncertainty (Table 15).

\section{INFINITE-HORIZON MODEL}

This section's main focus is showing that in an infinite-horizon, small open economy model, the sign of the third derivative is irrelevant to generating positive precautionary savings. There are two basic features of infinite-horizon models under uncertainty that are key to understanding how these kinds of models differ from their finite-horizon counterparts. First, the relationship between the real interest rate and the rate of time preference, and, second, the borrowing constraints implied by either Inada conditions or non-negativity constraints (in consumption).

Under uncertainty, a stationary equilibrium exists only if the real interest rate is lower than the subjective rate of time preference. When horizons are finite, whether the rate of time preference equals or exceeds the interest rate will only affect the shape of the consumption path. But this will not affect the existence of a well-defined equilibrium. As highlighted by Aiyagari (1994) under infinite horizon, if the interest rate is equal to or higher than the rate of time preference, agents will choose to accumulate an infinite amount of assets and average 
asset holdings will be infinite. Intuitively, when the real interest rate is higher than the rate of time preference, consumers want to postpone consumption to the future and be lenders. This will also be true in the case where the rate of time preference equals the real interest rate. Intuitively, under infinite horizon, there is always a positive probability of getting a sufficiently long string of bad endowment realizations; then, in order to maintain a smooth marginal utility across time, agents would accumulate an arbitrarily large amount of assets to buffer bad realizations of the shocks. ${ }^{10}$

Consequently, it is required that the real interest rate be lower than the rate of time preference for assets to be finite. This is a well-understood feature of infinite-horizon small open economy models under uncertainty. In other words, if the subjective discount factor is equal to the real interest rate, the model induces a random walk component in the equilibrium marginal utility of consumption and net foreign assets. This result is completely independent of the sign of the third derivative and is only caused by the infinite horizon and a borrowing constraint.

It is also important to note that Inada conditions on preferences (i.e., CES preferences) implicitly introduce a borrowing constraint because consumption can never be zero. This is usually called the natural borrowing limit. Having an ad hoc borrowing limit (usually for calibration purposes) affects average asset holdings, but does not affect the qualitative behavior of the economy.

Consider a simple small open economy inhabited by a representative agent. There is only one tradable good. The representative agent can borrow and lend in international capital markets at a given real interest rate. Markets are incomplete, since the only financial instrument available is a one-period non-contingent bond that pays the world's real interest rate.

The agent's preferences are given by:

$$
E_{0}\left\lfloor\sum_{t=0}^{\infty} \beta^{t} u\left(c_{t}\right)\right\rfloor
$$

where the period utility function is the one presented in Section II.

The economy chooses consumption and foreign assets to maximize (21) subject to the following constraints. The resource constraint,

$$
c_{1}=(1+r) b_{t}+y_{t}-b_{t+1}-A
$$

\footnotetext{
${ }^{10}$ See Chamberlain and Wilson (1984) or Ljungqvist and Sargent (2004) for details.
} 
where $c_{t}, y_{t}$, and $b_{t}$ denote, respectively, consumption, endowment, and net foreign asset position in period $t$, and $r$ is the world's real interest rate which is taken as given and constant. $A$ is a positive parameter needed in order to insure that consumption is never higher $\operatorname{than} \bar{c}=\sqrt{a / 3 b}$. Following Durdu et. al. (2007), this parameter can be thought of as lump sum absorption.

Since this particular class of preferences doesn't display an Inada condition, a non-negativity constraint $\left(c_{t} \geq 0\right)$ is needed. The ad-hoc debt limit is given by:

$$
b_{t} \geq \phi
$$

where $\phi$ is the borrowing limit for net foreign assets. ${ }^{11}$

The economy's income, $y$, is subject to random shocks, which follow a first-order Markov chain.

\section{A. Equilibrium}

If the borrowing limit is not binding, the optimality condition for the competitive equilibrium is

$$
u^{\prime}\left(c_{t}\right)=(1+r) \beta E\left[u^{\prime}\left(c_{t+1}\right)\right]
$$

which has the usual interpretation. The marginal benefit of saving an additional unit of the endowment is equal to the marginal cost of not consuming that unit.

A competitive equilibrium is defined by stochastic sequences $\left[c_{t}, b_{t+1}\right]$ such that the Euler equation (23) and the resource constraint (22) are both satisfied for all $t$.

\section{B. Parameterization}

The parameterization is exactly the same as in Durdu et al. (2007) except for the borrowing limit and the lump sum absorption $(A)$, which were chosen to match the level of net foreign assets and the level of consumption of the Mexican economy. The preference parameters (i.e., risk aversion) were chosen to match the standard deviation of consumption.

\footnotetext{
${ }^{11}$ Since the qualitative behavior of the economy is not affected by whether the borrowing limit is the natural borrowing limit or an ad-hoc debt limit, for simplicity, I use an ad-hoc debt limit for the numerical exercise.
} 
Table 17. Infinite-Horizon Model Parameterization

\begin{tabular}{clc}
\hline Notation & Parameter/Variable & Value \\
$\beta$ & Discount factor & 0.94 \\
$r$ & Interest rate & 0.059 \\
$a$ & Preference parameter & 8.35 \\
$b$ & Preference parameter & 0.333 \\
$\sigma_{\mathrm{e}}$ & Std dev of GDP innovations & 0.026 \\
$\rho$ & Autocorrelation of GDP & 0.597 \\
$\phi$ & Ad hoc debt limit & -1.34 \\
$A$ & Lump sum absorption & -0.77 \\
\hline
\end{tabular}

\section{Results}

In this section, I present and explain qualitative and quantitative results obtained with the model economy described above.

First, precautionary savings are positive despite the fact that preferences display a negative third derivative. Second, following Durdu, Mendoza, and Terrones (2007), it is easy to see that using this particular class of preferences does not substantially affect saving levels or the cyclical behavior of macroeconomic variables in the economy.

Our main interest is to assess the effects of (i) volatility, (ii) persistence, (iii) risk aversion, and (iv) interest rates, on the level of average asset holdings and therefore on precautionary savings. 
Table 18. Infinite-Horizon Model Moments

\begin{tabular}{lcccccc}
\hline & Baseline & rho=0.7 & sd=5\% & sd=2.5\% & $\boldsymbol{a}=\mathbf{6}$ & $\boldsymbol{r}=\mathbf{6 . 3 \%}$ \\
\hline Precautionary Savings & 0.92 & 0.94 & 1.05 & 0.88 & 0.98 & 1.12 \\
NFA Ratios & 0.31 & 0.30 & 0.22 & 0.34 & 0.27 & 0.16 \\
& & & & & & \\
Means & & & & & & \\
$\quad$ Output & 1.00 & 1.00 & 1.00 & 1.00 & 1.00 & 1.00 \\
$\quad$ Consumption & 0.69 & 0.69 & 0.70 & 0.68 & 0.69 & 0.70 \\
$\quad$ Foreign Assets & $-\mathbf{0 . 4 2}$ & $-\mathbf{0 . 4 0}$ & $-\mathbf{0 . 2 9}$ & $-\mathbf{0 . 4 6}$ & -0.36 & $-\mathbf{0 . 2 2}$ \\
$\quad$ Trade Balance & 0.31 & 0.31 & 0.29 & 0.32 & 0.31 & 0.30 \\
$\quad$ Current Account & 0.00 & 0.00 & 0.00 & 0.00 & 0.00 & 0.00 \\
Standard Deviation & & & & & & \\
$\quad$ Output & 3.29 & 3.62 & 6.26 & 2.47 & 3.22 & 3.19 \\
$\quad$ Consumption & 3.26 & 3.79 & 5.58 & 2.64 & 2.80 & 2.41 \\
$\quad$ Foreign Assets & 17.56 & 22.36 & 42.09 & 9.49 & 25.82 & 34.81 \\
$\quad$ Trade Balance & 5.48 & 5.75 & 11.87 & 3.59 & 6.40 & 7.24 \\
$\quad$ Current Account & 5.24 & 5.41 & 11.27 & 3.44 & 6.06 & 6.70 \\
Output Correlations & & & & & & \\
$\quad$ Consumption & 0.79 & 0.81 & 0.72 & 0.85 & 0.68 & 0.55 \\
$\quad$ Foreign Assets & 0.51 & 0.49 & 0.46 & 0.57 & 0.42 & 0.31 \\
$\quad$ Trade Balance & 0.75 & 0.69 & 0.78 & 0.69 & 0.79 & 0.84 \\
$\quad$ Current Account & 0.47 & 0.53 & 0.49 & 0.42 & 0.50 & 0.53 \\
Autocorrelations & & & & & & \\
$\quad$ Output & 0.55 & 0.64 & 0.54 & 0.55 & 0.55 & 0.54 \\
$\quad$ Consumption & 0.76 & 0.80 & 0.79 & 0.73 & 0.82 & 0.87 \\
$\quad$ Foreign Assets & 0.93 & 0.95 & 0.95 & 0.91 & 0.96 & 0.97 \\
$\quad$ Trade Balance & 0.47 & 0.57 & 0.49 & 0.40 & 0.51 & 0.55 \\
$\quad$ Current Account & 0.45 & 0.55 & 0.47 & 0.39 & 0.49 & 0.52 \\
& & & & & & \\
\hline
\end{tabular}

Column one shows the baseline, which uses the parameterization described above and the class of preferences considered throughout this study. The first thing to notice is that precautionary savings are positive regardless of the sign of the third derivative. This is shown in rows one and two of Table 18. The intuition for this result is that in an infinite-horizon model with a borrowing constraint, agents take into account that many different sequences of endowments are possible to realize; in particular, there is always a positive probability of receiving a very long sequence of the worst possible shock. If this is the case, the optimal response is to accumulate a large enough buffer stock of assets in order to smooth consumption (i.e., dissave) when needed. Therefore, average asset holdings are always higher under uncertainty than in a situation in which the endowment is completely certain. This result is independent of whether the marginal utility is convex (i.e., $u^{\prime \prime \prime}>0$ ), linear (i.e., $u^{\prime \prime \prime}=$ 0 ) or concave (i.e., $u^{\prime \prime \prime}<0$ ) and it is only a consequence of the infinite horizon and the borrowing constraint.

The qualitative effects of higher persistence, higher volatility, higher degree of risk aversion, and higher interest rates go in the standard direction. Higher persistence affects the volatility 
of GDP (higher persistence implies higher GDP volatility, because $\sigma_{y}^{2}=\sigma_{e}^{2} /\left(1-\rho_{y}^{2}\right)$ ), and therefore precautionary savings increase. As is standard for almost every class of preferences, and, in particular, for the ones with positive third derivative, it is almost always the case (with the exception of very particular examples shown in Huggett (2004)) that higher volatility increases precautionary savings (i.e., lower debt for this particular calibration).

Regarding risk aversion, for the class of preferences considered in this study, for a given $b$, it is the $a$ parameter that affects the degree of risk aversion (see the Appendix for details) and from Table 18 it is easy to observe that higher risk aversion (i.e., lower $a$ ) increases the level of precautionary savings. The most interesting thing to notice is that the coefficient of relative prudence is constant and does not depend on any preference parameters. This particular feature enables us to isolate the effect of risk aversion in the determination of precautionary savings.

Regarding the effect of interest rates, it is also possible to observe that higher interest rates increase average assets holdings (i.e., lower debt in this case). Interestingly enough, for an increase of less than one percentage point in the interest rate, the economy goes from having a 42 percent debt (as a fraction of GDP) to a 22 percent debt. The reason for this immense change is the particular relationship between average asset holdings and interest rates highlighted in Aiyagari (1994).

\section{FINITE-HORIZON MODEL}

A legitimate question is whether it is possible to generate precautionary savings in a finitehorizon model without changing the utility function across time. And the answer is yes, provided that the time horizon is long enough. It is easy to show that in a multi-period model, if the time horizon is long enough, agents will behave in the same way as in an infinitehorizon model. And the intuition for this is the following: it is very well understood that in these types of models, it is optimal to hit the borrowing constraint at certain moments in time for certain realizations of the endowment. Once the economy hits the borrowing limit, then it is not possible to do consumption smoothing until either a buffer stock of assets is built or the debt is reduced. Obviously, whether the economy actually hits the borrowing limit depends on the particular realization of the endowment shocks, but the fact of having a finite number of periods implies a lower probability of hitting the constraint, compared to the case of having infinite periods. Therefore (if the time horizon is relatively short) the higher the variance of the endowment, the fewer the incentives to save, given the preferences introduced in Section II. Moreover, if the number of periods is not very large, the chances to get a sufficiently large stream of bad shocks are smaller than the case where the time horizon is infinite.

In order to illustrate this result, we solve the small open economy model with finite horizon using the following parameterization: 
Table 19. Finite-Horizon Model Parameterization

\begin{tabular}{clc}
\hline Notation & Parameter/Variable & Value \\
$\beta$ & Discount factor & 0.98 \\
$r$ & Interest rate & 0.02 \\
$a$ & Preference parameter & 6 \\
$b$ & Preference parameter & 0.333 \\
$\sigma_{\mathrm{e}}$ & Std dev of GDP innovations & $0.05 / 0.35$ \\
$\rho$ & Autocorrelation of GDP & 0.6 \\
$\phi$ & Ad hoc debt limit & -2 \\
\hline
\end{tabular}

We solve the model under two alternative scenarios: low (0.05) and high (0.35) variance for the innovations of the endowment. We first solve a forty-period model $(T=40)$ and then a two-hundred-period model $(T=200)$ and compare the net foreign asset position corresponding to low and high level of uncertainty within each model.

Table 20. Forty-Period Model with Low Volatility

\begin{tabular}{lrrrr}
\hline & $Y$ & NFA & $C$ & \multicolumn{1}{c}{ CA } \\
\hline & & & & \\
mean & 1.4999 & -0.0756 & 1.4988 & -0.0004 \\
std dev & 0.0584 & 0.1673 & 0.0275 & 0.0497 \\
& & & & \\
\hline
\end{tabular}

Table 21. Forty-Period Model with High Volatility

\begin{tabular}{lrrrr}
\hline & $Y$ & NFA & $C$ & CA \\
\hline & & & & \\
mean & 1.5002 & -0.3501 & 1.4941 & -0.001 \\
std dev & 0.4198 & 0.6057 & 0.2818 & 0.2221 \\
& & & & \\
\hline
\end{tabular}

Table 22. Two-Hundred-Period Model with Low Volatility

\begin{tabular}{lrrrr}
\hline & $Y$ & NFA & $C$ & \multicolumn{1}{c}{ CA } \\
\hline & & & & \\
mean & 1.4997 & -0.6772 & 1.4863 & -0.0002 \\
std dev & 0.0699 & 0.5432 & 0.0309 & 0.0621 \\
\hline
\end{tabular}

Table 23. Two-Hundred-Period Model with High Volatility

\begin{tabular}{lrrrr}
\hline & $Y$ & NFA & $C$ & \multicolumn{1}{c}{ CA } \\
\hline mean & 1.5033 & -0.5447 & 1.4925 & -0.0001 \\
std dev & 0.4881 & 0.9056 & 0.3467 & 0.242 \\
\hline
\end{tabular}


As we can see from Tables 20 and 21, the agent has no incentive to save more under higher uncertainty simply because, given the stochastic process, the chances of hitting the borrowing constraint in such a short period of time $(T=40)$ are relatively low. There is not enough time to hit the borrowing constraint. On the other hand, from Tables 22 and 23, it is easy to see that for a longer time horizon $(T=200)$, even with a negative third derivative, the agent has incentive to save. The intuition for this result is that the effect of uncertainty (and a long time horizon) is larger than the effect of imprudence on precautionary savings. Despite being imprudent, knowing that the time horizon is relatively long, the agent decides to increase the amount of net foreign assets (i.e., reduce its debt) whenever uncertainty is higher (i.e., higher volatility of shocks).

\section{CONClusion}

This paper presents the first example of a particular class of preferences never considered before, neither in the macroeconomic nor in the precautionary savings literature. These preferences are characterized by a concave utility function which displays two salient features: first, agents are risk-averse, but imprudent (i.e., negative third derivative) and second, the coefficient of relative prudence is completely independent of any parameters related to the degree of risk aversion.

The advantage of characterizing preferences with an explicit utility function is twofold. First, it is possible to assess, both qualitatively and quantitatively, the effects of changes in volatility and persistence of shocks (i.e., it is possible to analyze, not only iid shocks, but more general structures for shocks), risk aversion, interest rates, and intertemporal distortions on the levels of precautionary savings in small open economies. And second, it is possible to isolate the effect on precautionary savings of an increase in risk aversion. This is a crucial difference with other classes of standard and widely used preferences (i.e., CES or exponential) in which parameters affecting the degree of risk aversion also affect the degree of relative prudence.

As shown in the numerical exercises conducted above, this particular class of preferences highlights the importance of different determinants of precautionary savings both in finite and infinite-horizon models. Unfortunately the widespread use of preferences displaying prudence (i.e., a positive third derivative) has, first, blurred the importance of isolating risk aversion as an important determinant of precautionary savings, and, second, led to the mistaken belief that it is the degree of prudence or imprudence (i.e., the sign of the third derivative) that determines precautionary savings. This is only true in two-period models. In models with more than two periods one can build examples where the combination of increasing risk aversion (across time), intertemporal distortions, and sufficiently high volatility offsets the effect of imprudence on precautionary savings. Moreover, provided the time horizon is long enough, the effect of uncertainty is stronger than the effect of imprudence, and higher uncertainty implies higher savings. In infinite-horizon models, the 
key ingredient is not the degree of prudence, but the interaction of three elementsuncertainty, infinite horizon, and borrowing constraints - regardless of whether agents are prudent or imprudent. 


\section{APPENDIX \\ Relative Prudence and Relative Risk Aversion}

The first, second and third derivatives of the utility function presented in Section II are:

$$
\begin{gathered}
u^{\prime}\left(c_{t}\right)=a-3 b c_{t}^{2} \\
u^{\prime \prime}\left(c_{t}\right)=-6 b c_{t} \\
u^{\prime \prime \prime}\left(c_{t}\right)=-6 b
\end{gathered}
$$

So, following Kimball (1990) the coefficient of relative prudence (CRP) is:

$$
\eta_{R}(c)=-\frac{u^{\prime \prime \prime}\left(c_{t}\right)}{u^{\prime \prime}\left(c_{t}\right)} c
$$

Thus, for this class of preferences, the coefficient of relative prudence is:

$$
\eta_{R}(c)=-\frac{-6 b}{-6 b c} c=-1
$$

So this utility function displays constant relative prudence. Furthermore, the coefficient of relative prudence is completely independent of the parameters defining the curvature and the degree of risk aversion.

Relative risk aversion is

$$
\theta_{R}(c)=-\frac{u^{\prime \prime}\left(c_{t}\right)}{u^{\prime}\left(c_{t}\right)} c,
$$

then, for this class of preferences

$$
\theta_{R}(c)=-\frac{-6 b c}{\left[a-3 b c^{2}\right]} c=\frac{6 b c^{2}}{\left[a-3 b c^{2}\right]}
$$

so, as long as $\left[a-3 b c^{2}\right]>0$, a lower $a$ implies a higher coefficient of relative risk aversion. 


\section{REFERENCES}

Aiyagari, Rao, 1994, Uninsured Idiosyncratic Risk and Aggregate Saving," Quarterly Journal of Economics, Vol. 109 (August), pp. 659-84.

Browning, Martin and Annamaria Lusardi, 1996. "Household Saving: Micro Theories and Micro Facts," Journal of Economic Literature, American Economic Association, vol. 34(4), pages 1797-1855, December.

Chamberlain, Gary and Charles A. Wilson, 2000, - Pptimal Intertemporal Consumption Under Uncertainty," Review of Economic Dynamics, Vol. 3 (July), pp. 365-395.

Durdu, Ceyhun Bora, Enrique G. Mendoza, and Marco E. Terrones, 2009, Precautionary Demand for Foreign Assets in Sudden Stop Economies: An Assessment of the New Mercantilism," Journal of Development Economics, Vol. 89 (July), pp. 194-209.

Huggett, Mark, and Sandra Ospina, 2001, Aggregate Precautionary Savings: When is the Third Derivative Irrelevant?," Journal of Monetary Economics, Vol. 48 (September), pp. 373-396.

Huggett, Mark, 2004, Precautionary Wealth Accumulation," Review of Economic Studies, Vol. 71 (July), pp. 769-781.

Kimball, Miles S., 1990, Precautionary Saving in the Small and in the Large," Econometrica, Vol. 58 (January), pp. 53-73.

Leland, Hayne E., 1968, Saving and Uncertainty: The Precautionary Demand for Saving," Quarterly Journal of Economics, Vol. 82 (August): 465-473.

Ljungqvist, Lars, and Thomas J. Sargent, 2004, Recursive Macroeconomic Theory (Cambridge, MA: MIT Press). 